\title{
Excellent research: challenging and expensive
}

\author{
J. T. Trevors $\cdot$ M. H. Saier
}

Published online: 2 April 2010

(C) Springer Science+Business Media, LLC 2010

Excellent research is immensely challenging and difficult to successfully complete. Nature's complex secrets are revealed very slowly, sometimes by accident and sometimes not at all. Research often requires that people are trained for more than a decade using the best equipment and supplies available. This is very expensive and requires that the personnel being trained are advised by excellent supervisors usually in the form of an advisory committee. Equipment and supplies are expensive as are the operation, calibration and maintenance of the equipment. Data analysis often requires powerful computing capabilities. Other expenses include publication costs, travel to study sites and meetings, student stipends and salaries for technical staff and postdoctoral fellows. Institutions have overhead fee structures that can be as high as one-hundred percent. Research is very expensive, and there are no guarantees the outcome will be of any scholarly significance and contribute to humanity through science.

Novel, discovery-oriented research is difficult to conduct even under optimal research conditions with sufficient funding to successfully complete the research. Now consider the situation in developing and poorer countries with limited infrastructure and financial resources for research and teaching. Countries that spend about a dollar per person per year on health care are definitely not capable of launching and maintaining scholarly research programs of national and

J. T. Trevors $(\bowtie)$

Department of Environmental Biology, University of Guelph, Guelph, ON NIG-2W1, Canada

e-mail: jtrevors@uoguelph.ca

M. H. Saier $(\square)$

Division of Biological Sciences, University of California at San

Diego, La Jolla, CA 92093-0116, USA

e-mail: msaier@ucsd.edu international stature. Yet, research and development are fundamentally important to every country and provide solutions to a multitude of problems/challenges.

Since numerous countries lack the necessary resources to implement $\mathrm{R}$ and $\mathrm{D}$ programs, it appears the only mechanism for poorer countries to conduct meaningful public $\mathrm{R}$ and $\mathrm{D}$ is with the initial and most likely continuing international assistance of wealthy developed countries. This is easier said than done, but it can be done, and in some countries, this happens to some degree. There simply needs to be more international research collaboration with the bills being paid for by the wealthier nations. This is an excellent form of international foreign aid and assistance and can build trust between individuals and countries. Sharing in discoveries and applications that benefit humanity is most rewarding. Consider that all counties are affected by global climate change, human population growth, depletion of nonrenewable resources, infectious diseases, an AIDS pandemic and a very likely influenza pandemic, problems of waste and sewage disposal, potable water infrastructure, transportation infrastructure, public health infrastructure, and the list goes on. The wealthier nations must commit to ambitious and generous programs of international $R$ and $D$ to benefit all of humanity. It is most likely that the most pressing problems are population growth, global climate change, poverty, hunger, public health, agriculture and education. Poorer nations cannot solve these immense problems on their own. The solutions lie in international collaborations funded by the wealthier nations. Remember, the problems facing humanity do not stop at national borders.

What are the obstacles to international widespread $\mathrm{R}$ and $\mathrm{D}$ funded by the wealthier nations and even some corporations? Some possible answers include nationalism, national security, competition, greed, mistrust, dictatorships not democratic governments, limited funding, lack of 
political leadership, and there are people who simply do not want to share knowledge and solutions. The task is large, and it will not be easy, but it is doable. There will always be issues of national security, but these can be dealt, and they can evolve to include new strategies. Sharing wealth, knowledge, solutions, implementing universal birth control and resources for the good of humanity may be the only solution to ensure our common, shared, biosphere can be maintained and improved for future generations. 